\title{
Mitral valve surgery in the US Veterans Administration health system: 10-year outcomes and trends
}

\author{
Faisal G. Bakaeen, MD, , ,,c,d A. Laurie Shroyer, PhD, MSHA, ${ }^{\text {eff }}$ Marco A. Zenati, MD, MSc, , ,h \\ Vinay Badhwar, MD, ${ }^{i}$ Vinod H. Thourani, MD,${ }^{j}$ James S. Gammie, MD, ${ }^{\mathrm{k}}$ Rakesh M. Suri, MD, DPhil, \\ Joseph F. Sabik III, MD, ${ }^{\mathrm{d}}$ A. Marc Gillinov, MD, ${ }^{\mathrm{d}}$ Danny Chu, MD, ${ }^{1}$ Shuab Omer, MD, ${ }^{\mathrm{a}, \mathrm{b}}$ \\ Mary T. Hawn, MD, ${ }^{\mathrm{m}}$ G. Hossein Almassi, MD, ${ }^{\mathrm{n}, \mathrm{o}}$ Lorraine D. Cornwell, MD, ${ }^{\mathrm{a}, \mathrm{b}}$ \\ Frederick L. Grover, MD, ${ }^{\mathrm{p}, \mathrm{q}}$ Todd K. Rosengart, MD, ${ }^{\mathrm{a}, \mathrm{b}, \mathrm{c}}$ and Laura Graham, $\mathrm{MPH}^{\mathrm{r}, \mathrm{s}}$
}

\section{ABSTRACT}

Objective: To compare mitral valve repair (MVRepair) and mitral valve replacement (MVReplace) trends in the Veterans Affairs (VA) Surgical Quality Improvement Program.

Methods: Trends were compared by bivariate analyses, followed by backward stepwise selection and multivariable logistic modeling to determine the effect of preoperative comorbidities and facility-level factors on MVRepair (vs MVReplace) rate. A subgroup analysis focused on patients who underwent elective surgery for isolated primary degenerative mitral regurgitation. Propensity matching was done in the overall and primary degenerative cohorts.

Results: From October 2000 to October 2013, 4165 veterans underwent MVRepair $(\mathrm{n}=2408)$ or MVReplace $(\mathrm{n}=1757)$ for MV disease of any cause at 40 VA medical centers (procedural volume, 0-29/y; median 7/y). The MVRepair percentage increased from $48 \%$ in 2001 to $63 \%$ in $2013(P<.001)$. MVRepair rates varied widely among centers; center volume explained only $19 \%$ of this variation after adjustment for case $\operatorname{mix}\left(\mathrm{R}^{2}=0.19, P=.005\right)$. Unadjusted 30-day and 1-year mortality rates were lower after MVRepair than after MVReplace (3.5\% vs $4.8 \%, P=.04 ; 9.8 \%$ vs $12.1 \%, P=.02)$. Among the propensity-matched patients $(\mathrm{n}=2520), 30$-day and 1-year mortality were similar after MVRepair and MVReplace. In the propensity-matched primary degenerative subgroup $(\mathrm{n}=664)$, unadjusted long-term mortality for up to 10 years postoperatively was lower after MVRepair $(28 \%$ vs $37 \%, P=.003)$, as was risk-adjusted long-term mortality (hazard ratio, $0.78 ; 95 \%$ confidence interval, $0.61-1.01$ ).

Conclusions: In the VA Health System, mortality after MV operations is low. Despite the survival advantage associated with MV repair in primary mitral regurgitation, repair is infrequent at some centers, representing an opportunity for quality improvement. (J Thorac Cardiovasc Surg 2018;155:105-17)

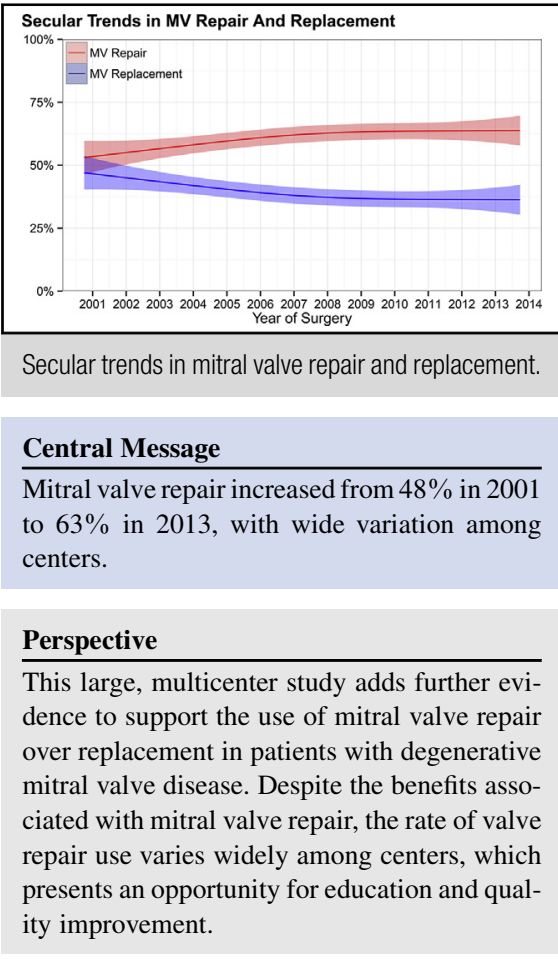

See Editorial Commentary page 118.

See Editorial page 80.

\footnotetext{
From the ${ }^{\mathrm{a}}$ Department of Surgery, Baylor College of Medicine; ${ }^{\mathrm{b}}$ The Michael E. DeBakey VA Medical Center; and ${ }^{\mathrm{c}}$ Department of Cardiovascular Surgery, Texas Heart Institute, Houston, Tex; ${ }^{\mathrm{d}}$ Department of Thoracic and Cardiovascular Surgery, Cleveland Clinic, Cleveland, Ohio; ${ }^{\mathrm{e}}$ Department of Surgery, Stony Brook Medicine, Stony Brook; and ${ }^{\mathrm{f}}$ Research and Development Office, Northport VA Medical Center, Northport, NY; ' Department of Surgery, Brigham and Women's Hospital; and ${ }^{\mathrm{h}}$ Harvard Medical School, Boston, Mass; ${ }^{\mathrm{i}}$ Division of Cardiothoracic Surgery, West Virginia University, Morgantown, WVa; ${ }^{\mathrm{j}}$ Division of Cardiothoracic Surgery, Emory University, Atlanta, Ga; ${ }^{\mathrm{k}}$ Division of Cardiac Surgery, University of Maryland School of Medicine, Baltimore, Md; 'Division of Cardiac Surgery, Department of Cardiothoracic Surgery, University of Pittsburgh School of Medicine, Pittsburgh, Pa; ${ }^{\mathrm{m}}$ Department of Surgery, Stanford University, Palo Alto, Calif; ${ }^{\mathrm{n}}$ Division of Cardiothoracic Surgery, Medical College of Wisconsin; and ${ }^{\circ}$ Zablocki VA Medical Center, Milwaukee, Wis; ${ }^{\mathrm{P}}$ Department of Surgery, University of Colorado Denver; and ${ }^{\mathrm{q}}$ Denver VA Medical Center, Aurora, Colo; ${ }^{\mathrm{r}}$ The
}

Birmingham and Tuscaloosa Health Services Research \& Development Program, Birmingham VA Medical Center; and ${ }^{\mathrm{s}}$ Department of Surgery, University of Alabama at Birmingham, Birmingham, Ala.

The content of this manuscript does not represent the opinion of Surgical Quality Data Use Group (SQDUG) or the Department of Veterans Affairs.

Read at the 96th Annual Meeting of The American Association for Thoracic Surgery, Baltimore, Maryland, May 14-18, 2016.

Received for publication May 20, 2016; revisions received July 11, 2017; accepted for publication July 28, 2017; available ahead of print Oct 23, 2017.

Address for reprints: Faisal G. Bakaeen, MD, Department of Thoracic and Cardiovascular Surgery, Cleveland Clinic, 9500 Euclid Ave, Cleveland, OH 44195 (E-mail: Bakaeef@ccf.org). $0022-5223 / \$ 36.00$

Copyright (C) 2017 by The American Association for Thoracic Surgery https://doi.org/10.1016/j.jtcvs.2017.07.089 


\section{Abbreviations and Acronyms \\ $\mathrm{CABG}=$ coronary artery bypass grafting \\ CI $=$ confidence interval \\ CPT $=$ Current Procedural Terminology \\ ICD-9 = International Classification of \\ Diseases, Ninth Revision \\ $\mathrm{IQR}=$ interquartile range \\ MR = mitral regurgitation \\ MV $\quad=$ mitral valve \\ MVRepair = mitral valve repair \\ MVReplace $=$ mitral valve replacement \\ STS ACSD $=$ Society of Thoracic Surgeons Adult Cardiac Surgery Database \\ VA $\quad=$ Veterans Affairs \\ VASQIP = Veterans Affairs Surgical Quality Improvement Program}

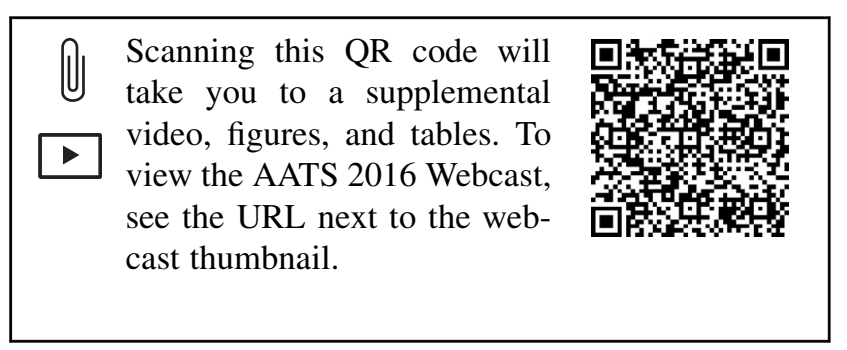

According to the Society of Thoracic Surgeons Adult Cardiac Surgery Database (STS ACSD), 57.4\% of all isolated mitral valve (MV) procedures reported in 2015 were MV repairs, although this rate was greater $(75 \%)$ when the pathology was degenerative or annular dilatation. ${ }^{1}$ More repairs are performed than replacements because mitral regurgitation (MR) is the most common mitral pathology in patients who undergo MV surgery in North America, 2,3 and mitral valve repair (MVRepair) is now widely favored over mitral valve replacement (MVReplace) in patients with primary degenerative MR. In such patients, MVRepair is associated with better outcomes and avoids the complications associated with prosthetic valve replacement. ${ }^{4-7}$

Mitral surgery volume has been shown to predict greater use of repair and better MV surgery outcomes. ${ }^{3,8}$ Therefore, calls have been made to set yearly MVRepair volume thresholds for surgeons and institutions, ${ }^{9}$ and some have suggested establishing referral centers and regionalizing MV care. $^{10,11}$

Whereas the volume, trends, and outcomes of mitral procedures at nongovernmental hospitals are well documented by the STS ACSD and are reported in numerous publications, ${ }^{2,3,5,7}$ little is known about the practice in the Veterans Affairs (VA) Health System, the largest federal health system in the country. The primary objective of this study was to evaluate trends in MVRepair and MVReplace in the VA system. Secondary objectives were to evaluate outcomes of MVRepair versus MVReplace when performed electively to treat primary $\mathrm{MR}$, and to determine whether MV procedure volume is associated with likelihood of MVRepair.

\section{METHODS}

The Veterans Affairs Surgical Quality Improvement Program (VASQIP) prospectively collects preoperative, intraoperative, postoperative, and outcomes data on all patients who undergo cardiac surgery at any of 43 VA cardiac surgery centers in the United States. The cardiac-specific component of VASQIP, previously known as the Continuous Improvement in Cardiac Surgery Program, is well established and validated. ${ }^{12}$

After obtaining institutional review board approval and waiver of informed consent, we requested and received approval for the study from the Department of Veterans Affairs Surgical Quality Data Use Group. Data were retrospectively reviewed from 4165 patients in VASQIP who underwent MVRepair or MVReplace with or without coronary artery bypass grafting (CABG) from October 1, 2000, to October 1, 2013. Patients were excluded who underwent reoperative cardiac surgery, any concomitant valve or great-vessel operation, or any other cardiac procedure except for surgical ablation for atrial fibrillation. In addition, we excluded patients from 3 centers that did not consistently report cardiac surgery data for every year of the study period.

\section{Variables}

Standard VASQIP data fields and definitions were used. In addition to clinical datasets, VASQIP incorporates International Classification of Diseases, Ninth Revision (ICD-9) and Current Procedural Terminology (CPT) codes that were used to supplement information on diagnosis and valve-related procedures. In addition to the applicable VASQIP nurse-abstracted variables shown in Table 1, the VA Corporate Data Warehouse inpatient and outpatient tables were queried for evidence of valvular disease in the 2 years before each MV operation by using the following ICD-9 diagnosis codes: Rheumatic 394.1, 395.0, 395.1, 395.2, 395.9, 396.0, 396.1, 396.2, 396.3, 396.8, 396.9, 397.0, 397.1 or Stenotic $394.0,394.1,394.2,396.0,396.1,746.5$. These variables were not only included as covariates in the analysis but also used to identify patients for subgroup analyses. The VA inpatient and outpatient tables also were queried for diagnosis codes indicating a recent history of atrial fibrillation in the 6 months preceding the MV operation (ICD-9: 427.3). Finally, the VA Vital Status dataset was used to obtain mortality data for all identified MV operations through June 2015, which allowed long-term follow-up of mortality.

The main exposure of interest was occurrence of an MVReplace or MVRepair procedure during the study period. Mitral surgery type was defined by using the VASQIP-defined variables for MVRepair and MVReplace. To identify any MV procedures not coded as the primary procedure, concurrent CPT codes for other cardiac operations were queried for CPT 33430 to identify MV replacements and for CPT 33420, 33422, 33425, 33426, and 33427 to identify MV repairs.

Primary degenerative MR was defined as nonstenotic, nonrheumatic, and nonischemic in origin (ejection fraction $\geq 35 \%$, no history of myocardial infarction or $\mathrm{CABG}$ ). Procedure designation was based on an as-treated approach because VASQIP does not capture failed repair attempts at the time of the index procedure. In the primary degenerative subgroup, we excluded patients who underwent ablation for atrial fibrillation (data were available only after 2005) or any nonelective 
TABLE 1. Comorbidities and operative characteristics associated with MV surgery type

\begin{tabular}{|c|c|c|c|c|}
\hline & Overall, $N=4165$ & MV repair, $n=2408$ & MV replacement, $\mathbf{n}=1757$ & $P$ value \\
\hline \multicolumn{5}{|l|}{ Patient characteristics } \\
\hline Age, y & $63.7 \pm 9.8$ & $63.7 \pm 9.6$ & $63.9 \pm 10.2$ & .48 \\
\hline BMI, $\mathrm{kg} / \mathrm{m}^{2}$ & $27.4 \pm 5.2$ & $27.5 \pm 5.1$ & $27.3 \pm 5.4$ & .25 \\
\hline Male sex & $4056(97.4)$ & $2360(98.0)$ & $1696(96.5)$ & .003 \\
\hline \multicolumn{5}{|l|}{ Preoperative comorbidities } \\
\hline Serum creatinine, $\mathrm{mg} / \mathrm{dL}$ & $1.3 \pm 0.8$ & $1.2 \pm 0.8$ & $1.3 \pm 0.9$ & .03 \\
\hline Peripheral vascular disease & $601(14.4)$ & $294(12.2)$ & 307 (17.5) & $<.001$ \\
\hline Cerebral vascular disease & $681(16.4)$ & $369(15.3)$ & $312(17.8)$ & .04 \\
\hline COPD & $1282(30.8)$ & $699(29.0)$ & $583(33.2)$ & .004 \\
\hline Current smoker & $1014(24.4)$ & $556(23.1)$ & $458(26.1)$ & .03 \\
\hline Diabetes & & & & .64 \\
\hline None & $3293(79.1)$ & $1901(79.0)$ & $1392(79.2)$ & \\
\hline Oral & 477 (11.5) & $284(11.8)$ & $193(11.0)$ & \\
\hline Insulin & $395(9.5)$ & $223(9.3)$ & $172(9.8)$ & \\
\hline Hypertension & $3340(80.4)$ & $1957(81.5)$ & $1383(78.9)$ & .04 \\
\hline Recent atrial fibrillation & $1138(27.3)$ & $671(27.9)$ & 467 (26.6) & .36 \\
\hline Angina & & & & .13 \\
\hline Class I-II & $3100(74.4)$ & $1771(73.6)$ & 1329 (75.6) & \\
\hline Class III-IV & $1065(25.6)$ & $637(26.5)$ & $428(24.4)$ & \\
\hline LV ejection fraction & & & & $<.001$ \\
\hline$\geq 35 \%$ & $3472(85.7)$ & $1920(81.6)$ & $1552(91.4)$ & \\
\hline$<35 \%$ & $578(14.3)$ & $432(18.4)$ & $146(8.6)$ & \\
\hline NYHA & & & & .01 \\
\hline Class I-II & $1771(42.5)$ & $1064(44.2)$ & 707 (40.2) & \\
\hline Class III-IV & $2394(57.5)$ & $1344(55.8)$ & $1050(59.8)$ & \\
\hline Previous myocardial infarction & & & & $<.001$ \\
\hline None & 3077 (73.9) & $1727(71.7)$ & $1350(76.8)$ & \\
\hline$\leq 7 \mathrm{~d}$ before surgery & $999(24.0)$ & $630(26.2)$ & $369(21.0)$ & \\
\hline$>7 \mathrm{~d}$ before surgery & $89(2.1)$ & $51(2.1)$ & $38(2.2)$ & \\
\hline PTCA & & & & .24 \\
\hline None & $4142(99.4)$ & $2398(99.6)$ & $1744(99.3)$ & \\
\hline $12-72 \mathrm{~h}$ before surgery & $14(0.3)$ & $5(0.2)$ & $9(0.5)$ & \\
\hline$<12 \mathrm{~h}$ before surgery & $9(0.2)$ & $5(0.2)$ & $4(0.2)$ & \\
\hline Current digoxin use & $582(14.0)$ & $336(14.0)$ & $246(14.0)$ & .97 \\
\hline IVNTG within $48 \mathrm{~h}$ & $69(1.7)$ & $37(1.5)$ & $32(1.8)$ & .48 \\
\hline Mitral regurgitation & & & & $<.001$ \\
\hline Mild/none & $178(4.3)$ & $75(3.1)$ & $103(5.9)$ & \\
\hline Moderate & $587(14.2)$ & $389(16.2)$ & $198(11.4)$ & \\
\hline Severe & $3366(81.5)$ & $1931(80.6)$ & $1435(82.7)$ & \\
\hline Mitral stenosis & $593(14.2)$ & $225(9.3)$ & $368(20.9)$ & $<.001$ \\
\hline Rheumatic pathology & $956(23.0)$ & $529(22.0)$ & $427(24.3)$ & .08 \\
\hline Active endocarditis & $181(4.3)$ & $36(1.5)$ & $145(8.3)$ & $<.001$ \\
\hline Functional status & & & & .004 \\
\hline Independent & $3683(88.4)$ & $2153(89.4)$ & $1530(87.1)$ & \\
\hline Partially dependent & $412(9.9)$ & $227(9.4)$ & $185(10.5)$ & \\
\hline Totally dependent & $70(1.7)$ & $28(1.2)$ & $42(2.4)$ & \\
\hline ASA class & & & & .74 \\
\hline$<4$ & $2833(68.1)$ & $1644(68.3)$ & $1189(67.8)$ & \\
\hline $4-5$ & $1329(31.9)$ & $764(31.7)$ & $565(32.2)$ & \\
\hline Maze procedure (FY2005 onward) & $392(13.2)$ & $362(20.3)$ & $30(2.5)$ & $<.001$ \\
\hline Preoperative use of IABP & $155(3.7)$ & $79(3.3)$ & $76(4.3)$ & .08 \\
\hline Calculated estimate of $30-\mathrm{d}$ operative mortality & $5.3 \pm 5.9$ & $4.8 \pm 4.5$ & $5.9 \pm 7.3$ & $<.001$ \\
\hline Calculated estimate of $30-\mathrm{d}$ operative morbidity & $21.3 \pm 11.7$ & $20.8 \pm 9.9$ & $22.2 \pm 13.7$ & $<.001$ \\
\hline
\end{tabular}


TABLE 1. Continued

\begin{tabular}{|c|c|c|c|c|}
\hline & Overall, $N=4165$ & MV repair, $n=2408$ & MV replacement, $n=1757$ & $P$ value \\
\hline \multicolumn{5}{|l|}{ Operative characteristics } \\
\hline Case status & & & & $<.001$ \\
\hline Elective & $3794(91.1)$ & $2214(92.0)$ & $1580(90.0)$ & \\
\hline Urgent & $294(7.1)$ & $170(7.1)$ & $124(7.1)$ & \\
\hline Emergent & $75(1.8)$ & $23(1.0)$ & $52(3.0)$ & \\
\hline Concomitant CABG & $1879(45.1)$ & $1164(48.3)$ & $715(40.7)$ & $<.001$ \\
\hline Total bypass time, $\min$ & $165.6 \pm 62.0$ & $161.8 \pm 58.0$ & $170.8 \pm 66.6$ & $<.001$ \\
\hline Total ischemic time, min & $119.7 \pm 49.4$ & $116.2 \pm 46.8$ & $124.5 \pm 52.3$ & $<.001$ \\
\hline
\end{tabular}

Values are represented as mean $\pm \mathrm{SD}$ or n (\%). $M V$, Mitral valve; $B M I$, body mass index; $C O P D$, chronic obstructive pulmonary disease; $L V$, left ventricle; $N Y H A$, New York Heart Association; PTCA, percutaneous transluminal coronary angioplasty; IVNTG, intravenous nitroglycerin; $A S A$, American Society of Anesthesiologists; $F Y$, fiscal year; IABP, intra-aortic balloon pump; $C A B G$, coronary artery bypass grafting.

procedure. An ejection fraction of less than $35 \%$ was considered to indicate cardiomyopathy-related MR.

\section{Outcome Measures}

The primary outcome measure was MVRepair (vs MVReplace) rate during the study period. All-cause mortality was evaluated at 30 days postoperatively and long term. The maximum follow-up time for the cohort was 14.8 years, with a mean follow-up of $6.0 \pm 3.8$ years (follow-up data were available through June 2015). Other outcome measures included perioperative morbidity and length of hospital stay as assessed by VASQIP. The predicted risk of mortality and the predicted risk of perioperative morbidity are incorporated into the VASQIP database and are estimated from contemporary national VA data. ${ }^{13}$

\section{Statistics}

Univariate and bivariate statistics of all covariates were examined for the study cohort (Table 1). With the exception of data on Maze procedures, which were not collected before 2005 and therefore were missing for $29 \%$ of the cohort, the prevalence of missing data did not exceed $3 \%$ for any variable in this analysis. Multiple imputation was not undertaken because the missing data did not differ by MV repair status or outcomes and thus were perceived to be missing at random; therefore, complete case analysis was used. Trends across time were examined as proportions of MVRepair per fiscal year, and a test for trend and a $\chi^{2}$ test were used to determine whether any year was different from the others. Risk-adjusted trends in MVRepair across fiscal years were calculated by the use of generalized estimating equations incorporating center as a random effect and any statistically significant confounders.

Characteristics associated with MV surgery type were examined with $\chi^{2}$ test statistics for categorical variables and Wilcoxon rank sums for continuous variables. A propensity for MVRepair was developed by using a logistic model. The propensity model included all measured baseline covariates: age, male sex, body mass index, American Society of Anesthesiologists classification, serum creatinine, peripheral vascular disease history, cerebral vascular disease history, chronic obstructive pulmonary disease history, current smoking, diabetes, hypertension requiring medication, recent atrial fibrillation, left ventricular ejection fraction, New York Heart Association functional classification, previous myocardial infarction, percutaneous transluminal coronary angioplasty within 72 hours before surgery, current digoxin use, intravenous nitroglycerine within 48 hours, MR, mitral stenosis, rheumatic pathology, active endocarditis, functional status at the time of surgery, preoperative intra-aortic balloon pump use, operative case status, and the hospital at which the surgery was performed. One MVReplace patient was matched to each MVRepair patient to within 0.2 standard deviations of the calculated MVRepair propensity. Propensity matching produced subgroups of 2520 and 664 matched patients ( $67 \%$ of possible matches) in the overall and primary degenerative cohorts, respectively.
To examine variation across centers, the proportion of total MV operations that were repairs was calculated for each VA hospital and study year. Total center volume was considered to be the total number of MV procedures performed at that center during the study period. Case-mixadjusted, center-specific MVRepair rates were estimated from the facility random effect of the best-fit mixed model for MVRepair described previously. Variation in unadjusted and adjusted MVRepair rates was examined by generating histograms and scatterplots. Pearson correlation coefficients were used to examine the association between center volume and proportion of MVRepairs.

Logistic regression was used to estimate the odds for each 30-day outcome among MVRepair operations as compared with MVReplace operations. Logistic models also were used to examine the association between MV surgery type and 30-day mortality. Both the unadjusted odds and the odds from the propensity-matched subset were calculated for each outcome examined.

Lastly, Kaplan-Meier curves were used to examine long-term mortality up to 10 years after discharge while accounting for censoring at the end of follow-up (June 1, 2015), with time 0 starting on the day of surgery. Adjusted hazard ratios for mortality after MVRepair versus MVReplace were estimated by using Cox proportional hazards after confirmation that all assumptions for Cox proportional hazards models were met. Covariates included in the multivariate Cox proportional hazards model were determined by the use of forward stepwise selection to avoid overfitting the model. Characteristics associated with MV surgery type in bivariate analyses were considered as potential covariates in the final multivariate Cox proportional hazards model. The aforementioned analyses were completed concurrently for both the overall cohort and for each subgroup of patients with a different cause of MR. All analyses were conducted with SAS version 9.4 (SAS Institute, Inc, Cary, NC) and R version 3.0.1 (https://www.r-project.org/). A $P$ value $<.05$ was considered to be statistically significant.

\section{RESULTS}

\section{Trends in MVRepair Versus MVReplace}

Entire cohort. During the period from 2001 to 2013, 2408 (57.8\%) MVRepair and 1757 (42.2\%) MVReplace procedures were performed at $40 \mathrm{VA}$ cardiac surgery centers. The proportion of MV repairs increased from $48 \%$ in 2001 to $63 \%$ in $2013(P<.001$; Figure $1, A)$, and this increase remained significant after adjustment for other potential confounders $(P=.02)$ that changed across time. The median number of mitral operations performed was 7/center/y (range 0-29), and the median number of MV repairs was 4/center/y (range 0-21). The rate of MV repair varied widely among centers (Figure 1, B); center volume 

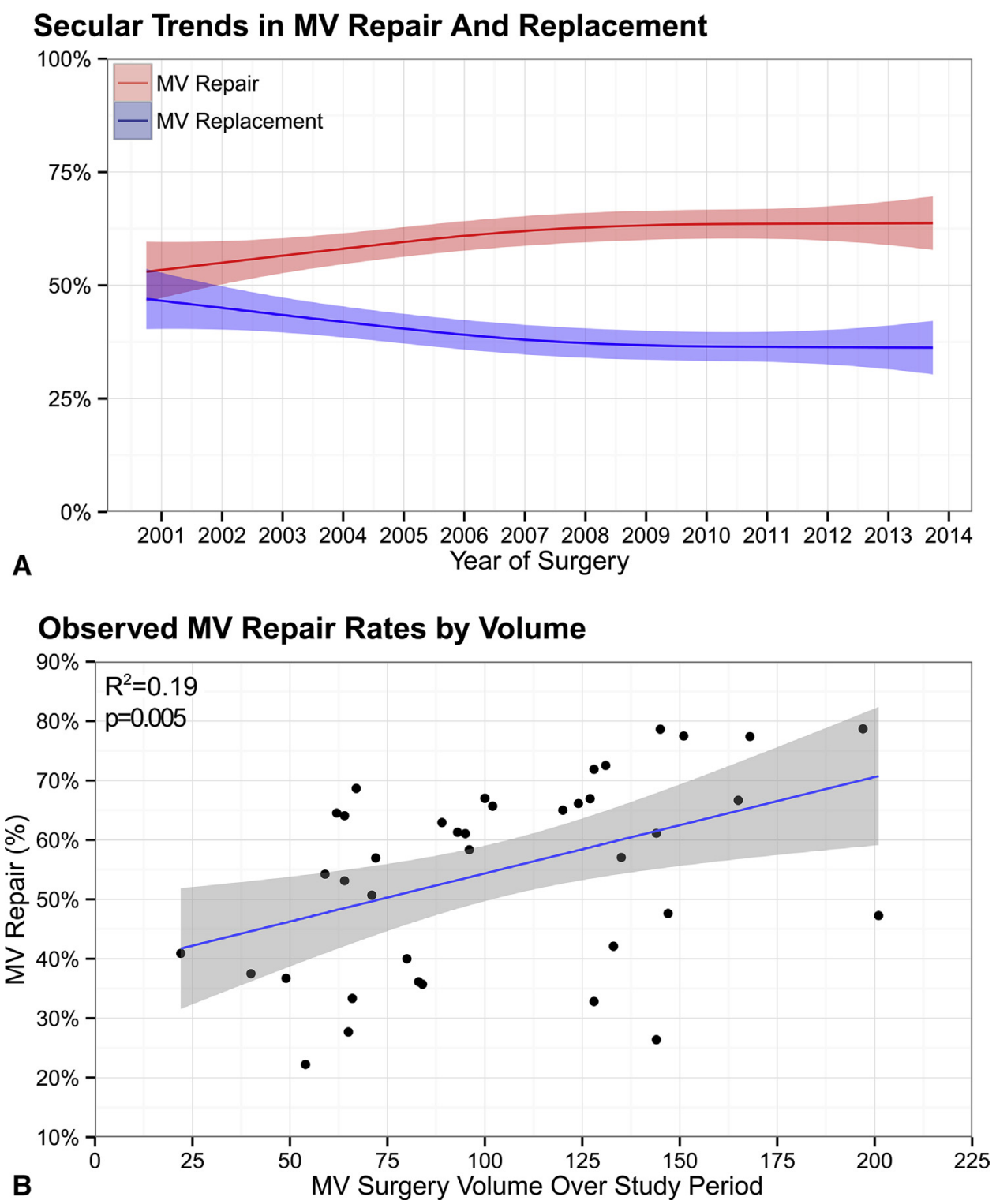

FIGURE 1. In the entire cohort ( $\mathrm{N}=4165)$, (A) trends in use of MVRepair versus MVReplace and (B) effect of center volume on MVRepair rates. $M V$, Mitral valve.

explained only $19 \%$ of the total variation in facility-level MVRepair rates after adjustment for case mix $\left(\mathrm{R}^{2}=0.19\right.$, $P=.005)$.

Isolated primary degenerative subgroup. In this subgroup $(\mathrm{n}=990)$, the proportion of MVRepairs increased over time, from $55 \%$ in 2001 to $65 \%$ in 2013 , but this increase was not significant $(P=.11$; Figure $2, A)$. Rates of MVRepair varied widely among centers (Figure 2, B); center volume had no effect on facility-level MVRepair rates after adjustment for case mix $\left(\mathrm{R}^{2}=0.001, P=.81\right)$. Other causes of MR. The trends in MVRepair versus MVReplace in patients with rheumatic valve disease and those with MR related to ischemia, cardiomyopathy, and active endocarditis are displayed in Figure E1. To varying extents, the use of MVRepair relative to MVReplace increased with time for all MR pathologies except active endocarditis.

\section{Patient Risk Profile and Outcomes}

Entire cohort $(\mathbf{N}=\mathbf{4 1 6 5})$. There were many differences between the MVRepair and MVReplace groups (Table 1). In general, compared with the MVReplace patients, the MVRepair patients had a lower prevalence of comorbidities, including peripheral vascular disease, cerebrovascular disease, chronic obstructive pulmonary disease, New York Heart Association class III/IV, mitral stenosis, and active endocarditis. Likewise, the MVRepair group had lower VASQIP-predicted risks of mortality 


\section{Secular Trends in MV Repair And Replacement}

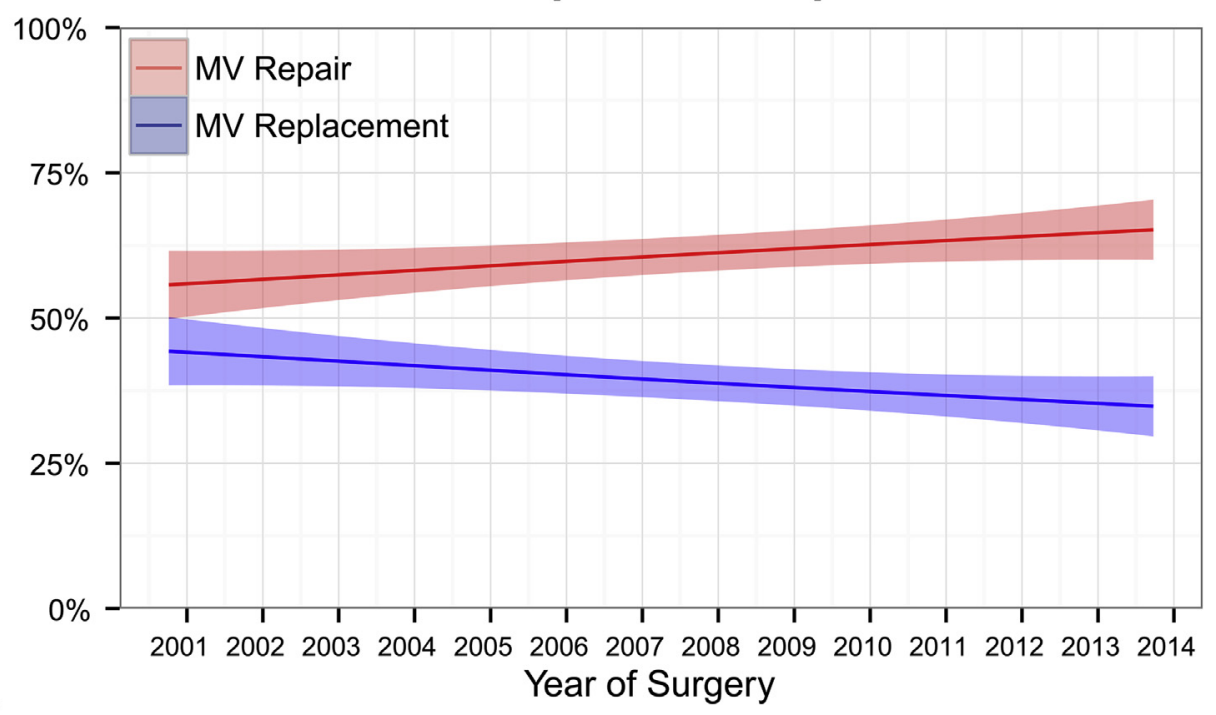

A

Year of Surgery

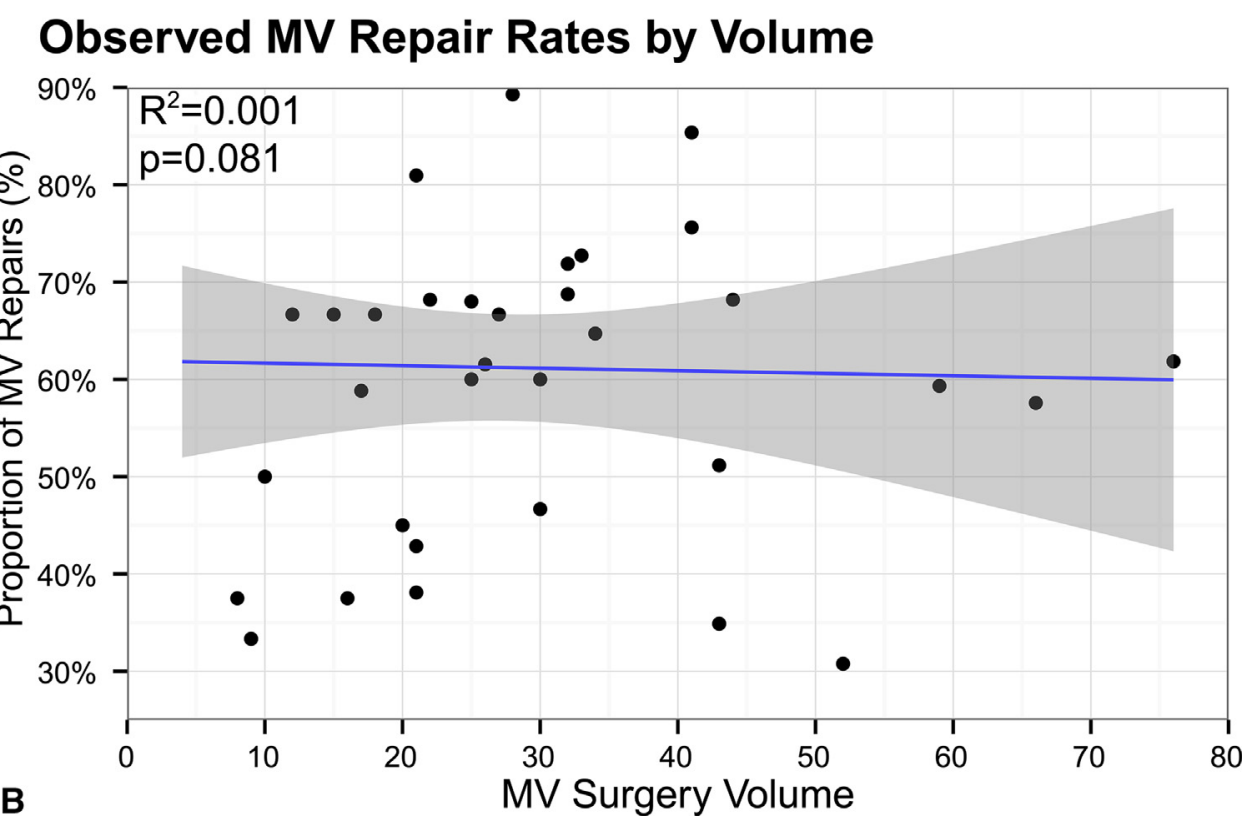

FIGURE 2. In the subgroup of patients with primary degenerative MR ( $\mathrm{n}=990)$, (A) trends in use of MVRepair versus MVReplace and (B) effect of center volume on MVRepair rates. $M V$, Mitral valve.

$(4.8 \%$ vs $5.9 \%, P<.001)$ and morbidity $(20.8 \%$ vs $22.2 \%$, $P<.001)$. The propensity-matched patients had similar baseline risk profiles (Table E1).

Compared with the MVReplace group, the MVRepair group had similar or lower occurrences of various perioperative morbidities except for a greater incidence of new mechanical circulatory support $(5.0 \%$ vs $3.5 \%$, $P=.02$ ) (Table 2). After risk adjustment, the only significant difference in morbidity outcomes between the 2 groups was a reduced risk of perioperative myocardial infarction (odds ratio $0.43,95 \%$ confidence interval [CI] $0.20-0.93$ ). Median postoperative length of stay was shorter for MVRepair patients (8 d [interquartile range $\{\mathrm{IQR}\}$, 6-14 d]) than for MVReplace patients (10 d [IQR, $7-15 \mathrm{~d}])(P<.001)$, and this difference in length of stay persisted after risk adjustment.

Unadjusted 30-day and 1-year mortality rates were lower for the MVRepair (vs MVReplace) patients (3.5\% vs $4.8 \%$, $P=.04$, and $9.8 \%$ vs $12.1 \%, P=.02$, respectively) (Table 2). After propensity matching, compared with MVReplace, MVRepair was associated with similar 30-day mortality (odds ratio, 0.82; 95\% CI, 0.55-1.21) and marginally lower 1-year mortality (hazard ratio, 0.80 ; $95 \%$ CI, 0.62-1.01). 
TABLE 2. Mortality and perioperative morbidities by MV surgery type in full cohort $(\mathbf{N}=4165)$ and propensity-matched subgroup $(\mathrm{n}=2520)$

\begin{tabular}{|c|c|c|c|c|c|}
\hline & \multirow[b]{2}{*}{ MV repair } & \multirow[b]{2}{*}{ MV replacement } & \multirow[b]{2}{*}{$P$ value } & \multicolumn{2}{|c|}{ Odds of MV repair compared with replacement } \\
\hline & & & & $\begin{array}{c}\text { Unadjusted } \\
\text { OR }(95 \% \text { CI })\end{array}$ & $\begin{array}{c}\text { Propensity matched } \\
\text { OR }(95 \% \text { CI })\end{array}$ \\
\hline Acute renal failure & $73(3.0)$ & $68(3.9)$ & .14 & $0.78(0.55-1.09)$ & $0.82(0.53-1.27)$ \\
\hline Reoperation for bleeding & $86(3.6)$ & $69(3.9)$ & .55 & $0.91(0.66-1.25)$ & $0.98(0.64-1.49)$ \\
\hline Stroke & $51(2.1)$ & $33(1.9)$ & .59 & $1.13(0.73-1.76)$ & $1.00(0.57-1.76)$ \\
\hline Mediastinitis & $18(0.8)$ & $14(0.8)$ & .86 & $0.94(0.47-1.89)$ & $0.80(0.31-2.04)$ \\
\hline Endocarditis & $5(0.2)$ & $7(0.4)$ & .26 & $0.52(0.16-1.64)$ & $0.20(0.02-1.71)$ \\
\hline Perioperative MI & $12(0.5)$ & $18(1.0)$ & .05 & $0.48(0.23-1.01)$ & $0.33(0.11-1.03)$ \\
\hline New MCS & $120(5.0)$ & $59(3.4)$ & .01 & $1.51(1.10-2.07)$ & $1.18(0.78-1.79)$ \\
\hline Cardiac arrest requiring $\mathrm{CPR}$ & $70(2.9)$ & $73(3.9)$ & .07 & $0.73(0.52-1.03)$ & $0.93(0.61-1.42)$ \\
\hline Ventilator support $>48 \mathrm{~h}$ & $304(12.6)$ & $269(15.3)$ & .01 & $0.80(0.67-0.95)$ & $0.78(0.62-0.98)$ \\
\hline Repeat ventilator within $30 \mathrm{~d}$ & $93(5.3)$ & $94(8.0)$ & .003 & $0.64(0.47-0.86)$ & $0.71(0.48-1.05)$ \\
\hline Tracheostomy & $55(2.3)$ & $55(3.1)$ & .09 & $0.72(0.49-1.06)$ & $0.63(0.38-1.06)$ \\
\hline $\begin{array}{l}\text { Postoperative length of stay, } d \text {, } \\
\text { median }(\mathrm{Q} 1-\mathrm{Q} 3)^{*}\end{array}$ & $8(6-14)$ & $10(7-15)$ & $<.001$ & $-2.28(-3.2$ to -1.4$)$ & $-2.72(-3.9$ to -1.5$)$ \\
\hline Death within $30 \mathrm{~d}$ & $84(3.5)$ & $84(4.8)$ & .04 & $0.72(0.53-0.98)$ & $0.82(0.55-1.21)$ \\
\hline Death within $180 \mathrm{~d} \dagger$ & & & & $0.71(0.57-0.87)$ & $0.74(0.57-0.97)$ \\
\hline Death within $1 \mathrm{y} \dagger$ & & & & $0.79(0.66-0.95)$ & $0.80(0.62-1.01)$ \\
\hline
\end{tabular}

Values are represented as mean $\pm \mathrm{SD}$ or n (\%). $M V$, Mitral valve; $O R$, odds ratio; $C I$, confidence interval; $M I$, myocardial infarction; $M C S$, mechanical circulatory support; $C P R$, cardiopulmonary resuscitation; $Q 1$, first quartile; $Q 3$, third quartile. *Postoperative length of stay was modeled by using generalized linear regression. Adjusted beta estimates (expressed in days) are presented instead of ORs. †Hazard ratios and $95 \%$ CIs are presented.

Survival analysis (Figure E2) showed lower long-term (10-year) mortality after MVRepair, even after adjustment for other risk factors (hazard ratio, 0.88; 95\% CI, $0.80-0.97, P=.01)$. This finding was confirmed in the propensity-matched cohort (Figure E3).

Primary degenerative subgroup $(\mathbf{n}=990)$. In the primary degenerative subgroup, MVRepair patients were younger (60.6 vs $62.5 \mathrm{y}, P=.002$ ) and more often had independent functional status $(97.2 \%$ vs $92.3 \%$, $P=.002)$. In addition, the MVRepair group had a lower prevalence of hypertension, advanced angina class, and congestive heart failure (Table 3).

There were no differences in the rates of various perioperative morbidities by MV surgery type (Table 4). However, MVRepair was associated with shorter median hospital length of stay (7 d [IQR, 5-10 d] vs $8 \mathrm{~d}$ [IQR, 6-12 d]; $P<.001$ ), and this difference persisted even after adjustment for other factors (Table 4).

Unadjusted and adjusted 30-day, 180-day, and 1-year mortality rates were similar between the 2 groups (Table 4). Survival analysis (Figure E2) showed lower long-term (10-year) mortality after MVRepair, even after adjustment for other risk factors (hazard ratio, 0.78; 95\% CI, 0.61-1.01). This finding was confirmed in the propensity-matched cohort (Figure E3).

Other causes of MR. Mortality data stratified by different causes of MR show no significant difference in outcomes between MVRepair and MVReplace (Table E2), but the number of patients in each subgroup is small.

Survival curves for unmatched and matched patients with different causes of MR are displayed in Figures E2 and E3, respectively. Compared with MVReplace, MVRepair was associated with better long-term survival in patients with rheumatic MR but not in patients with MR of other causes.

\section{DISCUSSION}

This study serves as a comprehensive evaluation of MV surgery practices in the VA system. It produced several important findings, including a progressive increase in the use of MVRepair over time. In fact, the increased rate of MVRepair from 48\% in 2001 to $63 \%$ in 2013 mirrors the trend revealed by analyses of the STS ACSD, in which the rate of MVRepair increased from $42 \%$ in $2000^{7}$ to $62 \%$ between 2007 and $2010,{ }^{2}$ and to $75 \%$ for primary MR from 2011 to $2014 .^{1}$ Interestingly, the trend in the use rate of off-pump coronary artery bypass surgery at VA centers $^{14}$ also mirrored that of the STS reporting centers, ${ }^{15}$ indicating that the introduction and adoption of novel surgical procedures occur in tandem at VA and non-VA facilities. This is expected, because all VA cardiac programs are affiliated with academic centers, and some share faculty and educational programs with their university affiliates. $^{16,17}$ 
TABLE 3. Comorbidities and operative characteristics associated with MV surgery type (primary degenerative MR patients only)

\begin{tabular}{|c|c|c|c|c|}
\hline & $\begin{array}{c}\text { Overall } \\
\mathbf{N}=990\end{array}$ & $\begin{array}{c}\text { MV repair } \\
\mathbf{n}=\mathbf{5 7 2}\end{array}$ & $\begin{array}{l}\text { MV replacement } \\
\quad n=418\end{array}$ & $P$ value \\
\hline \multicolumn{5}{|l|}{ Patient characteristics } \\
\hline Age, y & $63.7 \pm 9.8$ & $60.6 \pm 9.8$ & $62.5 \pm 10.4$ & .002 \\
\hline BMI, $\mathrm{kg} / \mathrm{m}^{2}$ & $27.4 \pm 5.2$ & $27.3 \pm 5.0$ & $27.5 \pm 5.2$ & .59 \\
\hline Male sex & $958(96.8)$ & 554 (96.9) & 404 (96.7) & .86 \\
\hline \multicolumn{5}{|l|}{ Preoperative comorbidities } \\
\hline Serum creatinine, $\mathrm{mg} / \mathrm{dL}$ & $1.3(0.8)$ & $1.1(0.6)$ & $1.2(0.9)$ & .09 \\
\hline Peripheral vascular disease & $81(8.2)$ & $41(7.2)$ & $40(9.6)$ & .17 \\
\hline Cerebral vascular disease & $78(7.9)$ & $48(8.4)$ & $30(7.2)$ & .48 \\
\hline COPD & $223(22.5)$ & $117(20.5)$ & $106(25.4)$ & .07 \\
\hline Current smoker & $200(20.3)$ & $120(21.1)$ & $80(19.2)$ & .47 \\
\hline Diabetes & & & & .24 \\
\hline None & $885(89.4)$ & $519(90.7)$ & $366(87.6)$ & \\
\hline Oral & $66(6.7)$ & $32(5.6)$ & $34(8.1)$ & \\
\hline Insulin & $39(3.9)$ & $21(3.7)$ & $18(4.3)$ & \\
\hline Hypertension & $706(71.5)$ & $393(69.0)$ & $313(74.9)$ & .04 \\
\hline Recent atrial fibrillation & $207(20.9)$ & $105(18.4)$ & $102(24.4)$ & .02 \\
\hline Angina & & & & .02 \\
\hline Class I-II & $853(86.2)$ & $505(88.3)$ & $348(83.3)$ & \\
\hline Class III-IV & $137(13.8)$ & $67(11.7)$ & $70(16.8)$ & \\
\hline NYHA & & & & .01 \\
\hline Class I-II & $498(50.3)$ & $309(54.0)$ & $189(45.2)$ & \\
\hline Class III-IV & 492 (49.7) & $263(46.0)$ & $229(54.8)$ & \\
\hline Current digoxin use & $100(10.1)$ & $50(8.7)$ & $50(12.0)$ & .10 \\
\hline Mitral regurgitation & & & & .22 \\
\hline Mild/none & 0 & 0 & 0 & \\
\hline Moderate & $54(5.5)$ & $27(4.7)$ & $27(6.5)$ & \\
\hline Severe & $931(94.5)$ & $544(95.3)$ & $387(93.5)$ & \\
\hline Functional status & & & & .002 \\
\hline Independent & $942(95.2)$ & $556(97.2)$ & $386(92.3)$ & \\
\hline Partially dependent & $44(4.4)$ & $15(2.6)$ & $29(6.9)$ & \\
\hline Totally dependent & $4(0.4)$ & $1(0.2)$ & $3(0.7)$ & \\
\hline ASA class category & & & & .79 \\
\hline$<4$ & $554(56.0)$ & $318(55.6)$ & $236(56.5)$ & \\
\hline $4-5$ & $436(44.0)$ & $254(44.4)$ & $182(43.5)$ & \\
\hline Calculated estimate of $30-\mathrm{d}$ operative mortality & $5.3 \pm 5.9$ & $3.3 \pm 3.1$ & $2.9 \pm 2.7$ & .10 \\
\hline Calculated estimate of $30-\mathrm{d}$ operative morbidity & $21.3 \pm 11.7$ & $15.8 \pm 6.6$ & $13.9 \pm 6.4$ & $<.001$ \\
\hline \multicolumn{5}{|l|}{ Operative characteristics } \\
\hline Total bypass time (min) & $141.8 \pm 48.1$ & $136.5 \pm 46.2$ & $148.9 \pm 49.8$ & $<.001$ \\
\hline Total ischemic time (min) & $104.4 \pm 39.5$ & $100 \pm 36.2$ & $110.3 \pm 42.9$ & $<.001$ \\
\hline
\end{tabular}

Values are represented as mean $\pm \mathrm{SD}$ or $\mathrm{n}(\%) . M V$, Mitral valve; $B M I$, body mass index; $C O P D$, chronic obstructive pulmonary disease; $N Y H A$, New York Heart Association; ASA, American Society of Anesthesiologists.

When assessing procedure selection and outcomes of MV surgery, one should take into consideration the baseline risk profile of the population under evaluation and the type of valve lesion being treated. Veterans are predominantly male; female patients constitute less than $4 \%$ of patients who undergo MV surgery at the VA, in contrast to approximately $50 \%$ of the patients at centers that report to the STS ACSD. ${ }^{2,7}$ The prevalence of peripheral vascular disease, cerebrovascular disease, and chronic obstructive pulmonary disease in both the entire cohort and the patients with primary degenerative MR is greater than what has been previously reported in a nonveteran cohort. $^{2}$ In addition, more than one half of the VA's MV surgery patients undergo concomitant $\mathrm{CABG}$, reflecting the significant atherosclerotic burden in this population. In general, MVReplace patients were sicker and had a greater predicted risk of perioperative mortality and morbidity than MVRepair patients.

As to the type of valve lesion, as expected, the prevalence of mitral stenosis was greater in the MVReplace group 
TABLE 4. Mortality and perioperative morbidities by MV surgery type in all patients $(n=990)$ and propensity-matched patients $(n=664)$ with primary degenerative mitral regurgitation

\begin{tabular}{|c|c|c|c|c|c|}
\hline & \multirow[b]{2}{*}{ MV repair } & \multirow[b]{2}{*}{ MV replacement } & \multirow[b]{2}{*}{$P$ value } & \multicolumn{2}{|c|}{ Odds of MV repair compared with replacement } \\
\hline & & & & $\begin{array}{c}\text { Unadjusted } \\
\text { OR }(95 \% \text { CI })\end{array}$ & $\begin{array}{c}\text { Propensity matched } \\
\text { OR }(95 \% \text { CI })\end{array}$ \\
\hline Acute renal failure & $5(0.9)$ & $3(0.7)$ & .79 & $1.22(0.29-5.13)$ & $1.00(0.20-5.02)$ \\
\hline Reoperation for bleeding & $14(2.5)$ & $10(2.4)$ & .96 & $1.02(0.45-2.33)$ & $0.66(0.23-1.90)$ \\
\hline Stroke & $11(1.9)$ & $8(1.9)$ & .99 & $1.00(0.40-2.52)$ & $1.44(0.54-3.86)$ \\
\hline Mediastinitis & $1(0.2)$ & $2(0.5)$ & .39 & $0.36(0.03-4.03)$ & $0.50(0.04-5.55)$ \\
\hline Endocarditis & $2(0.4)$ & $3(0.7)$ & .42 & $0.49(0.08-2.92)$ & N/A* \\
\hline Perioperative MI & 0 & $2(0.5)$ & .10 & N/A & N/A \\
\hline New MCS & $5(0.9)$ & $4(1.0)$ & .89 & $0.91(0.24-3.42)$ & $1.25(0.33-4.72)$ \\
\hline Cardiac arrest requiring CPR & $6(1.1)$ & $6(1.4)$ & .58 & $0.73(0.23-2.27)$ & $1.20(0.36-4.01)$ \\
\hline Ventilator support $>48 \mathrm{~h}$ & $26(4.6)$ & $26(6.2)$ & .24 & $0.72(0.41-1.26)$ & $0.77(0.42-1.41)$ \\
\hline Repeat ventilator within $30 \mathrm{~d}$ & $13(3.1)$ & $12(4.2)$ & .44 & $0.73(0.33-1.63)$ & $0.52(0.19-1.43)$ \\
\hline Tracheostomy & $1(0.2)$ & $4(1.0)$ & .09 & $0.18(0.02-1.63)$ & N/A* \\
\hline $\begin{array}{l}\text { Postoperative length of stay, d, } \\
\text { median, Q1-Q3† }\end{array}$ & $7(5-10)$ & $8(6-12)$ & $<.001$ & $-2.06(-3.5$ to -0.6$)$ & $-1.55(-3.3$ to 0.2$)$ \\
\hline Death within $30 \mathrm{~d}$ & $8(1.4)$ & $7(1.7)$ & .73 & $0.83(0.30-2.31)$ & $1.41(0.44-4.51)$ \\
\hline Death within $180 \mathrm{~d} \ddagger$ & & & & $0.49(0.24-0.95)$ & $0.92(0.41-2.09)$ \\
\hline Death within $1 \mathrm{y} \ddagger$ & & & & $0.51(0.28-0.96)$ & $0.79(0.36-1.74)$ \\
\hline
\end{tabular}

Values are represented as mean $\pm \mathrm{SD}$ or n (\%). $M V$, Mitral valve; $O R$, odds ratio; $C I$, confidence interval; $N / A$, not available; $M I$, myocardial infarction; $M C S$, mechanical circulatory support; $C P R$, cardiopulmonary resuscitation; $Q 1$, first quartile; $Q 3$, third quartile. *An adjusted OR could not be calculated for these variables because none of the matched patients had these conditions. †Postoperative length of stay was modeled by using generalized linear regression. Adjusted beta estimates (expressed in days) are presented instead of ORs. $\ddagger$ Hazard ratios and $95 \%$ CIs are presented.

( $21.0 \%$ vs $9.4 \%, P<.001)$, a finding that is consistent with data from STS ACSD. ${ }^{2}$ We specifically focused on the subgroup of patients with primary degenerative MR because repair is known to be more feasible and effective in such patients than in patients with other valve pathologies. ${ }^{4}$ In our definition of primary degenerative MR, secondary (ischemic) MR was eliminated, a diagnosis for which MVReplace may offer a more durable surgical correction according to recent evidence from the Cardiothoracic Surgical Trials Network. ${ }^{18,19}$

In the primary degenerative MR subgroup, unadjusted and adjusted 30-day and 1-year mortality rates were similar between the 2 groups. However, longer-term mortality favors MVRepair, so we recommend the use of MVRepair over MVReplace whenever possible.

The variability in use of MVRepair among the 40 centers deserves careful evaluation. This variation was not fully explained by the differences in patient risk profile or valve pathology. In addition, the volume of MV operations at VA hospitals was an obvious area of interest to us in our efforts to explain this variation, because volume has been shown to correlate with mitral repair (vs replacement) rates. ${ }^{3,8}$ In an analysis of STS ACSD data obtained from 28,507 patients who underwent isolated MV surgery by 1088 surgeons at 639 hospitals, Bolling and colleagues ${ }^{3}$ reported a median of $5 \mathrm{MV}$ operations per surgeon per year (range, 1-166). There was substantial variability in repair rates among low-volume surgeons. Higher surgeon-level MV procedural volume was an independent predictor of MVRepair, with an apparent inflection point at 40 isolated mitral cases per surgeon per year. If this volume were used as the threshold for a center to qualify as a "mitral center of excellence," none of the VA centers would qualify, nor would more than one quarter of the centers that report to the STS ACSD. ${ }^{8}$ The requisite mitral volume recommended for surgeons and centers by a European expert consensus also exceeds the procedure numbers at even the busiest VA centers.

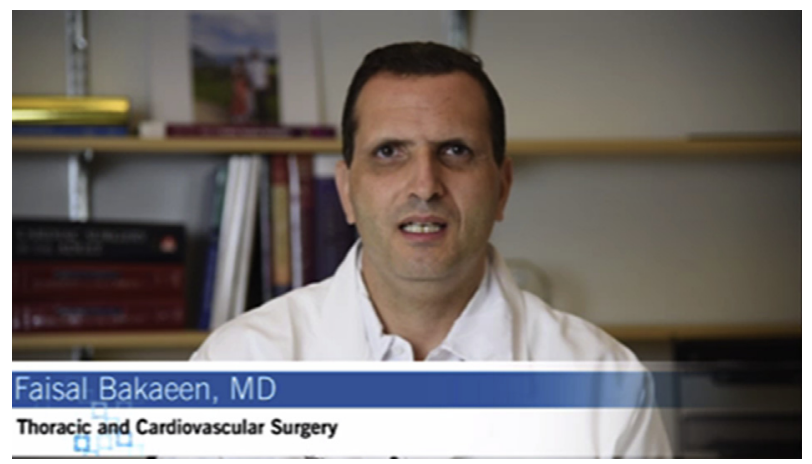

VIDEO 1. The lead author summarizes the study's findings and discusses their practical implications. Video available at: http://www.jtcvsonline.org/ article/S0022-5223(17)32144-X/fulltext. 
With a median rate of mitral operations of 7/center/y (range 0-29), VA centers are clearly low volume by any standard, but at the same time, VA hospitals are not typical low-volume community hospitals. The shared-faculty model and educational collaboration that exists between some VAs and their academic affiliates may help mitigate the effects of low volume at these hospitals, which would explain their good MV outcomes and our finding of an attenuated effect of center volume on repair rates. This argument is presumptive, however, because we do not have center identifiers or information about staffing models to allow us to confirm this hypothesis. In addition, we do not have surgeon-level data to ascertain individual surgeons' mitral volumes at VA centers or to determine whether those volumes are boosted by additional experience at the larger affiliate institution. These are important areas for future inquiry because there is a system-level opportunity to identify best practices and streamline mitral care. An in-depth evaluation of VA centers with high mitral repair rates could provide valuable information for running a successful low-volume mitral program that would be exportable to other VA or non-VA hospitals. This could translate into improved patient access and care (Video 1).

In addition to the lack of surgeon-level data, limitations of this study include the absence of detailed data relating to valve anatomy and precise pathology. Our definition of primary degenerative MR excludes older patients in whom the prevalence of combined coronary artery disease and degenerative MV disease is not insignificant. There was no follow-up echocardiographic data; therefore, the incidence of persistent or recurrent MR cannot be determined. Nonetheless, the results are consistent with the growing body of data demonstrating the advantages of MVRepair over MVReplace and the degree to which practice patterns vary among centers. As with other retrospective studies, it is impossible to eliminate all inherent biases, including intent-to-treat, in choosing between MVRepair and MVReplace, or to achieve perfect risk-adjustment when comparing outcomes between the 2 surgical approaches. The strength of this study is that it made use of a large, nonvoluntary, system-wide clinical database that captures all MV cases performed in the VA system.

\section{CONCLUSIONS}

Good outcomes are achieved with mitral surgery in the VA system despite the low-volume status of individual centers. What differentiates VA centers from one another is the variability in the use of MVRepair to treat degenerative MR, which is associated with at least an early survival advantage. Further studies are needed to investigate the reasons behind this variation and to identify opportunities to optimize MV care through education, training, and system-level care coordination.

\section{Webcast}

You can watch a Webcast of this AATS meeting presentation by going to: http://webcast.aats.org/2016/Video/Tuesday/0517-16_Hall_E_1040_Bakaeen-800.mp4.

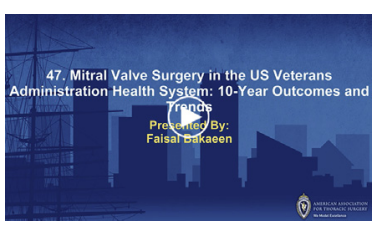

\section{Conflict of Interest Statement}

Authors have nothing to disclose with regard to commercial support.

Stephen N. Palmer, PhD, ELS, contributed to the editing of the manuscript.

\section{References}

1. Badhwar V, Rankin JS, He X, Jacobs JP, Gammie JS, Furnary AP, et al. The Society of Thoracic Surgeons Mitral Repair/Replacement Composite Score: A report of the Society of Thoracic Surgeons Quality Measurement Task Force. Ann Thorac Surg. 2016;101:2265-71.

2. Chatterjee S, Rankin JS, Gammie JS, Sheng S, O'Brien SM, Brennan JM, et al. Isolated mitral valve surgery risk in 77,836 patients from the Society of Thoracic Surgeons database. Ann Thorac Surg. 2013;96:1587-94; discussion 1594-5.

3. Bolling SF, Li S, O'Brien SM, Brennan JM, Prager RL, Gammie JS. Predictors of mitral valve repair: clinical and surgeon factors. Ann Thorac Surg. 2010;90: 1904-11; discussion 12.

4. Nishimura RA, Otto CM, Bonow RO, Carabello BA, Erwin JP III, Guyton RA, et al. 2014 AHA/ACC guideline for the management of patients with valvular heart disease: a report of the American College of Cardiology/American Heart Association Task Force on Practice Guidelines. J Thorac Cardiovasc Surg. 2014;148:e1-132.

5. Badhwar V, Peterson ED, Jacobs JP, He X, Brennan JM, O'Brien SM, et al. Longitudinal outcome of isolated mitral repair in older patients: results from 14,604 procedures performed from 1991 to 2007. Ann Thorac Surg. 2012;94: 1870-7; discussion 1877-9.

6. Mick SL, Keshavamurthy S, Gillinov AM. Mitral valve repair versus replacement. Ann Cardiothorac Surg. 2015;4:230-7.

7. Gammie JS, Sheng S, Griffith BP, Peterson ED, Rankin JS, O'Brien SM, et al. Trends in mitral valve surgery in the United States: results from the Society of Thoracic Surgeons Adult Cardiac Surgery Database. Ann Thorac Surg. 2009; 87:1431-7; discussion 1437-9.

8. Gammie JS, O'Brien SM, Griffith BP, Ferguson TB, Peterson ED. Influence of hospital procedural volume on care process and mortality for patients undergoing elective surgery for mitral regurgitation. Circulation. 2007;115:881-7.

9. Bridgewater B, Hooper T, Munsch C, Hunter S, von Oppell U, Livesey S, et al Mitral repair best practice: proposed standards. Heart. 2006;92:939-44.

10. Adams DH, Anyanwu AC. Seeking a higher standard for degenerative mitral valve repair: begin with etiology. J Thorac Cardiovasc Surg. 2008;136:551-6.

11. McCarthy PM. When is your surgeon good enough? When do you need a "referent surgeon?" Curr Cardiol Rep. 2009;11:107-13.

12. Grover FL, Johnson RR, Shroyer AL, Marshall G, Hammermeister KE. The Veterans Affairs continuous improvement in cardiac surgery study. Ann Thorac Surg. 1994;58:1845-51.

13. Bakaeen FG, Chu D, de la Cruz KI, Gopaldas RR, Sansgiry S, Huh J, et al. Aortic valve replacement: mortality predictions of surgeons versus risk model. J Surg Res. 2010;163:1-6.

14. Bakaeen FG, Kelly RF, Chu D, Jessen ME, Ward HB, Holman WL. Trends over time in the relative use and associated mortality of on-pump and off-pump coronary artery bypass grafting in the Veterans Affairs system. JAMA Surg. 2013;148: 1031-6.

15. Bakaeen FG, Shroyer AL, Gammie JS, Sabik JF, Cornwell LD, Coselli JS, et al. Trends in use of off-pump coronary artery bypass grafting: results from the 
Society of Thoracic Surgeons Adult Cardiac Surgery Database. J Thorac Cardiovasc Surg. 2014;148:856-63. 864.e1; discussion 863-4.

16. Bakaeen FG, Huh J, LeMaire SA, Coselli JS, Sansgiry S, Atluri PV, et al. The July effect: impact of the beginning of the academic cycle on cardiac surgical outcomes in a cohort of 70,616 patients. Ann Thorac Surg. 2009;88:70-5.

17. Bakaeen FG, Stephens EH, Chu D, Holman WL, Vaporciyan AA, Merrill WH, et al. Perceptions regarding cardiothoracic surgical training at Veterans Affairs hospitals. J Thorac Cardiovasc Surg. 2011;141:1107-13.

18. Acker MA, Parides MK, Perrault LP, Moskowitz AJ, Gelijns AC, Voisine P, et al. Mitral-valve repair versus replacement for severe ischemic mitral regurgitation. N Engl J Med. 2014;370:23-32.

19. Goldstein D, Moskowitz AJ, Gelijns AC, Ailawadi G, Parides MK, Perrault LP, et al. Two-year outcomes of surgical treatment of severe ischemic mitral regurgitation. N Engl J Med. 2016;374:344-53.

Key Words: mitral valve, mitral valve repair, mitral valve replacement, volume, outcomes, trends

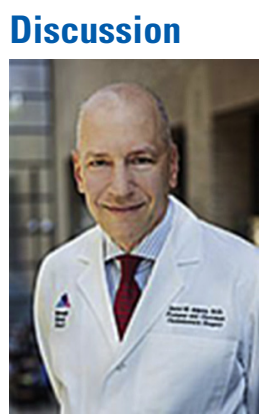

Dr D. Adams (New York, NY). Faisal, I think I'll skip the preamble today because I took a few extra minutes of the Association's time yesterday having a little talk with Tirone, so I'm just going to get straight to some observations and a few questions for you.

You know, when I got this manuscript, I was very excited because I saw this Veterans. I play country music every day. I love the Veterans. And I saw that author list of all these experts in mitral surgery and experts in the STS database, and I couldn't wait to open up and learn more.

And I want to challenge you a little bit at the beginning about how you presented this in the manuscript and today and how we get to your last point, which is really provide better care. Is that a deal?

Let's start with the statistics. I'm not drinking the Kool-Aid. You're comparing low volume with low volume. That's like me saying, and it's true, I have a 3-year-old. He's in a play group. He's the youngest kid in the play group. The ages are 3 years to 3.6 years. They're all young.

You're comparing all low volume. You can't say there was no volume relationship because you don't have any difference in volume. These are all low-volume centers the way we measure volume today in terms of procedures. Comment?

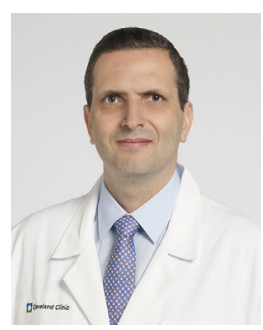

Dr Faisal G. Bakaeen (Cleveland, Ohio). Yes, I mean, they're all low-volume centers. I totally agree with you. And we've commented about that during our presentation and in the manuscript. That doesn't necessarily translate to low-volume surgeons because of the shared faculty model that exists in virtually all of those VAs.
Dr Adams. We're going to get to that in a minute. We'll talk about the shared faculty.

Now, the next thing I'll talk to you about is this presumptive degenerative group because I honestly think the whole group is a mismatch, and it's going to be hard to learn a lot. But the subgroup that you tried to define in degenerative is interesting. That's difficult to do.

I think in the future, all of our databases, including the Veterans' database, will let us do that. But you guys tried to make exclusions, excluding coronary patients and things like that to try to eliminate ischemic MR and rheumatic and infectious patients when you knew that.

But I was surprised, given the authorship and where the STS database is today, that you excluded atrial fibrillation and particularly tricuspid valve repair, which you didn't need to because I'm sure those data were available to you.

So why were you so prescriptive in terms of this presumptive population? Why not include isolated tricuspid ring with mitral, for example, or atrial fibrillation with mitral? Why did you exclude those patients?

Because my argument is then you're left with only 990 patients in 40 centers over multiple years, 2 cases per center per year in the degenerative group, you're so narrow that you're not really powered to teach us a lot. And it seems like you could have expanded that population, given the knowledge of that author list.

Dr Bakaeen. Well, you raise a very good point, but we wanted a clean sample set. And, in fact, we diluted our power by doing so because we wanted to make sure that the conclusions and the results that we come out with are watertight at the cost of being underpowered. But if you look at the entire sample, we had the power to demonstrate the benefits of mitral valve repair.

Dr Adams. That's right. The problem is the power-

Dr Bakaeen. And in answer to your question about atrial fibrillation and tricuspids, we made a comment in the manuscript that we did not track the Maze procedure until a later date through the study. And a small percentage of patients had tricuspid valve surgery, but we couldn't tell using the database whether it was repair or replacement; therefore, we dropped it. Again, we wanted a clean dataset.

Dr Adams. Okay. I know. But most of them would have been repair in the presumptive degenerative set.

Dr Bakaeen. Presumptively, yes.

Dr Adams. And you excluded 3 centers completely. We assume that would have lowered the rates of repair more, I'm guessing, if they're not reporting their data. At least it's a worry.

So I think your dataset is so narrowly defined it's hard to learn much, but we did learn something. And I want to get to this figure because I thought that was very interesting. Again, I'm just going to focus on the presumptive degenerative because at least that set is a little cleaner. I'm not going to criticize anybody for taking a patient to the operating room who's 
got a complex valve. He's got a lot of risk factors. You decide to do a valve replacement. That's not what we're talking about. We're talking about the degenerative group.

And when I look at your table for the degenerative group, this figure you briefly showed that I don't think most of the audience had a chance to look at it, you talked about the 75\% repair rate where we are today in the STS database for degenerative patients. I saw that author list, and you talk about you're associated with academic centers, and, therefore, you're bringing up the VA care.

But when I look at your curve in the paper, I count 2 centers that are over $75 \%, 1,2$ - sorry, I'm going to be accurate-4 centers of 40 that are $75 \%$ or over. And if I look at your top 10 volume centers just for the presumptive degenerative group, your top 10 centers, there are 2 centers that are 75 and over, and there are 2 centers that are 35 or under. Those are the highest 10 volume centers in the Veterans system. Only 2 hit 75 or over, and 2 are under 35 .

So it gets back to your last point. We all want to take better care of our Veterans, but certainly we need an action plan for these 2 centers that are below 35 .

And my other question is, given that author list, and several of those authors have published papers in degenerative disease with $100 \%, 99 \%$ repair rates, why isn't that number higher? Which surgeons from these academic centers are going to those hospitals to do the degenerative mitral valve patients?

Dr Bakaeen. I mean, you bring up an excellent point, and the purpose of this study is to identify opportunities for improvement, and there's definitely room for improvement.

So if you look at the average rather than look at specific centers, the VA is doing as good as the average center outside the VA. Is that good enough? No, that's not good enough. The bar should be set higher.

And in terms of what recommendation I might have to the VA system is, one, strengthen your affiliation with your academic affiliate, and this will certainly enhance the performance of specialized procedures such as complex mitral valve repair.

Second, join the STS database and publicly report the data. We need transparency. Why can't we have our VA database and dually submit to the STS? I've been a strong advocate of that for years.

And, third, education and training, because there are some people who still think in or outside the VA that all this stuff is based on expert opinions such as yours and others that repair is better than replacement, and then they cite the ischemic study that showed that replacement maybe better.

So they're saying, well, we need a randomized study to prove that for us. But, hey, we don't have a randomized study that proved to us that left internal thoracic artery is better than vein-we don't have it. We never had it. The 1986 paper by Fred Loop from the Cleveland Clinic and Toby Cosgrove was a retrospective study that changed practice of CABG as we know it ever since then.
So I guess what I'm trying to say is we just need to have better education to tell people, yes, repair is better for select patients, and yes, there are surgeons who are better at this than others.

Dr Adams. Faisal, again, I don't want to mix up the debate about ischemic repair and replacement with degenerative. The degenerative story is done. There's not going to be randomized trials, and every guideline says this and every expert says this.

So we need to repair degenerative valves, and in your series, $20 \%$ of patients who were class I or class II underwent replacement, and with those academic centers, it's too high.

And that gets you to my last question. Rather than trying to talk about 7 cases per year, we need to consolidate. That's obvious. You can't have 2 degenerative patients per year per Veterans hospital.

And given the affiliations, you bring up this point, they're all affiliated today, why not subcontract those patients to go regionally to the academic center in that region that is best for degenerative valve repair? I'm only focusing on degenerative patients.

And let's take it a step further. How about you're asymptomatic and you have bileaflet prolapse and you're our veteran and you're 50 years old, shouldn't that patient go to the regional center that's best for that and have the Veterans hospital or the government make a relationship to be able to provide that particular patient back here if we can't bring the surgeon there?

Dr Bakaeen. That's way beyond my pay grade, but I totally agree that this is food for thought and that policy should be in place so that veterans are educated consumers and that we help them and their referring physicians make informed decisions about care.

Now, I want to just bring up quickly a paper that Jim Gammie and Vinay Badhwar are on. It's a gap analysis that the American College of Cardiology conducted in terms of mitral valve repair care in the United States. One third of the primary care physicians had no idea where to refer these patients. They had a lack of specialists in mitral valve surgery in their area.

For the cardiologists themselves, $15 \%$ also had this problem, and for the specialist cardiologists, about $10 \%$ did. So the problem of access for care needs to be taken into consideration as well.

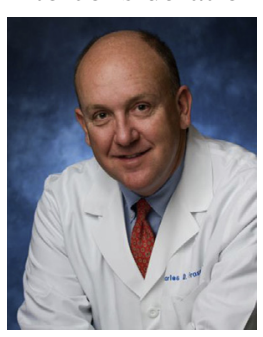

Dr C. Fraser (Houston, Tex). I just want to say I agree with Dr Adams, Faisal. It's a tremendous project that you've put together, but it's not beyond your pay grade to comment on this. You know, you have the bully pulpit, and I think what you've shown is that these patients aren't getting the opportunity that they would get at the Cleveland Clinic. And I don't think it's beyond your pay grade. 
Dr Bakaeen. To comment about it, I totally agree. But to do something about it, I can work on it.

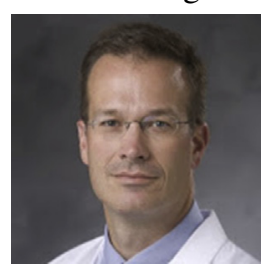

Dr J. Gaca (Durham, NC). I'm one of the surgeons at Duke and at the Durham VA. I just wondered if you had any data about repair versus replacement rates in faculty-affiliated VAs and independent VAs because that may be interesting.

Dr Bakaeen. I don't have that because I don't have identified centers, but from previous studies that I cite in my paper, the majority of VAs are affiliated with academic centers. Now, how strong is that affiliation and how real is that cross-pollination, I can't answer that, and that's the limitation.

Dr Moon. Let's have the final word from our combatant.

Dr Adams. Faisal, again, I congratulate you and your authors for bringing this forward. I think it's going to create more questions than answers, but I think you've started an important dialogue, and I think we'll move forward from there.

Dr Bakaeen. I need everyone's support to follow through with these recommendations. Thank you so much.

Readers who found these articles interesting may also like to read the following papers found in recent and future issues of our sister publications, Seminars in Thoracic and Cardiovascular Surgery and Operative Techniques in Thoracic and Cardiovascular Surgery!

\section{Acquired: Mitral Valve}

ORIGINAL SUBMISSION: Assessment of Mitral Valve Repair With Exercise Echocardiography: Artificial Chordae vs Leaflet Resection Sigurdur Ragnarsson. Semin Thoracic Surg 2017: 25-32.

Editorial Commentary: The Dance of 2 Devils: Mitral Valve Repair and Functional Mitral Stenosis Bobby Yanagawa. Semin Thoracic Surg 2017: 33-34.

ORIGINAL SUBMISSION: Comparative Histopathological Analysis of Mitral Valves in Barlow Disease and Fibroelastic Deficiency Jesper Hjortnaes. Semin Thoracic Surg 2016: 757-767.

Editorial Commentary: Angel in the Architecture and the Devil in the Details: Comparative Ultrastructure of Degenerative Mitral Valve Disease Tomasz A. Timek. Semin Thoracic Surg 2016: 768-769.

CURRENT READINGS: Similar Survival After Repair vs Replacement for Ischemic Mitral Regurgitation Hisato Takagi. Semin Thoracic Surg 2016: 748-756. 

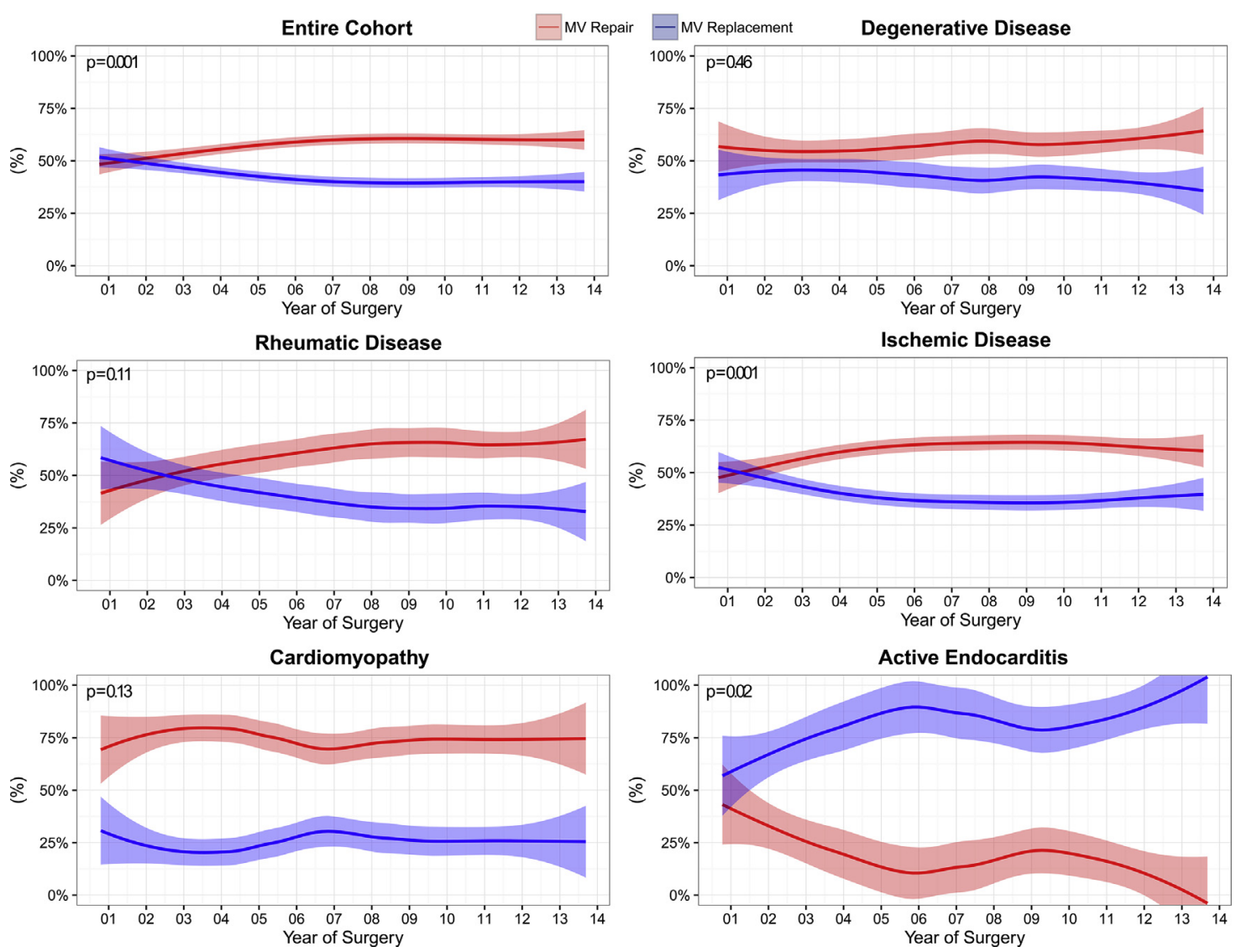

FIGURE E1. Trends in use of MVRepair (red) versus MVReplace (blue) for different causes of MR. MVRepair, Mitral valve repair; MVReplace, mitral valve replacement. 

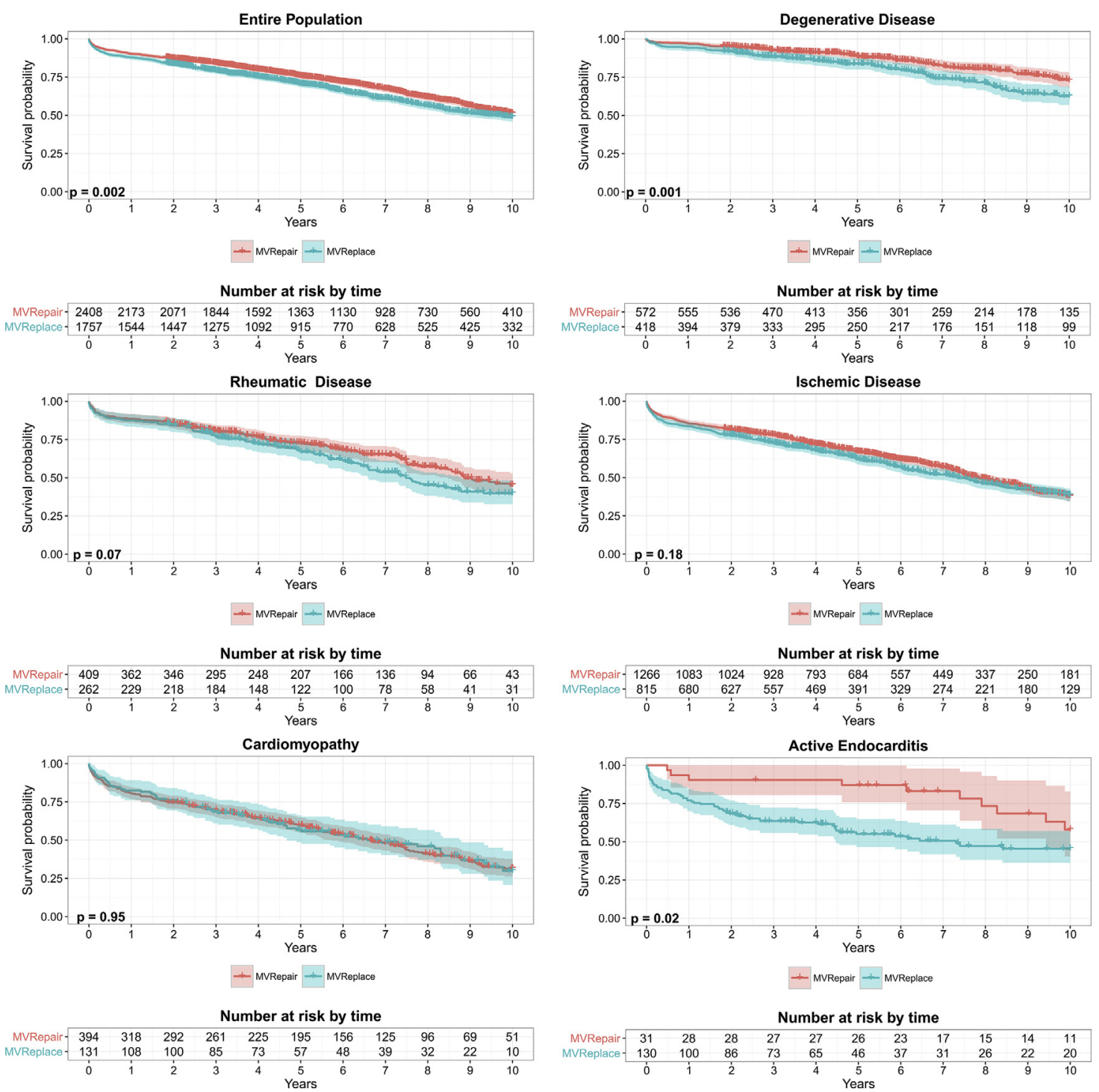

FIGURE E2. Kaplan-Meier survival curves for MVRepair (red) versus MVReplace (blue) for different causes of MR in all patients. MVRepair, Mitral valve repair; MVReplace, mitral valve replacement. 

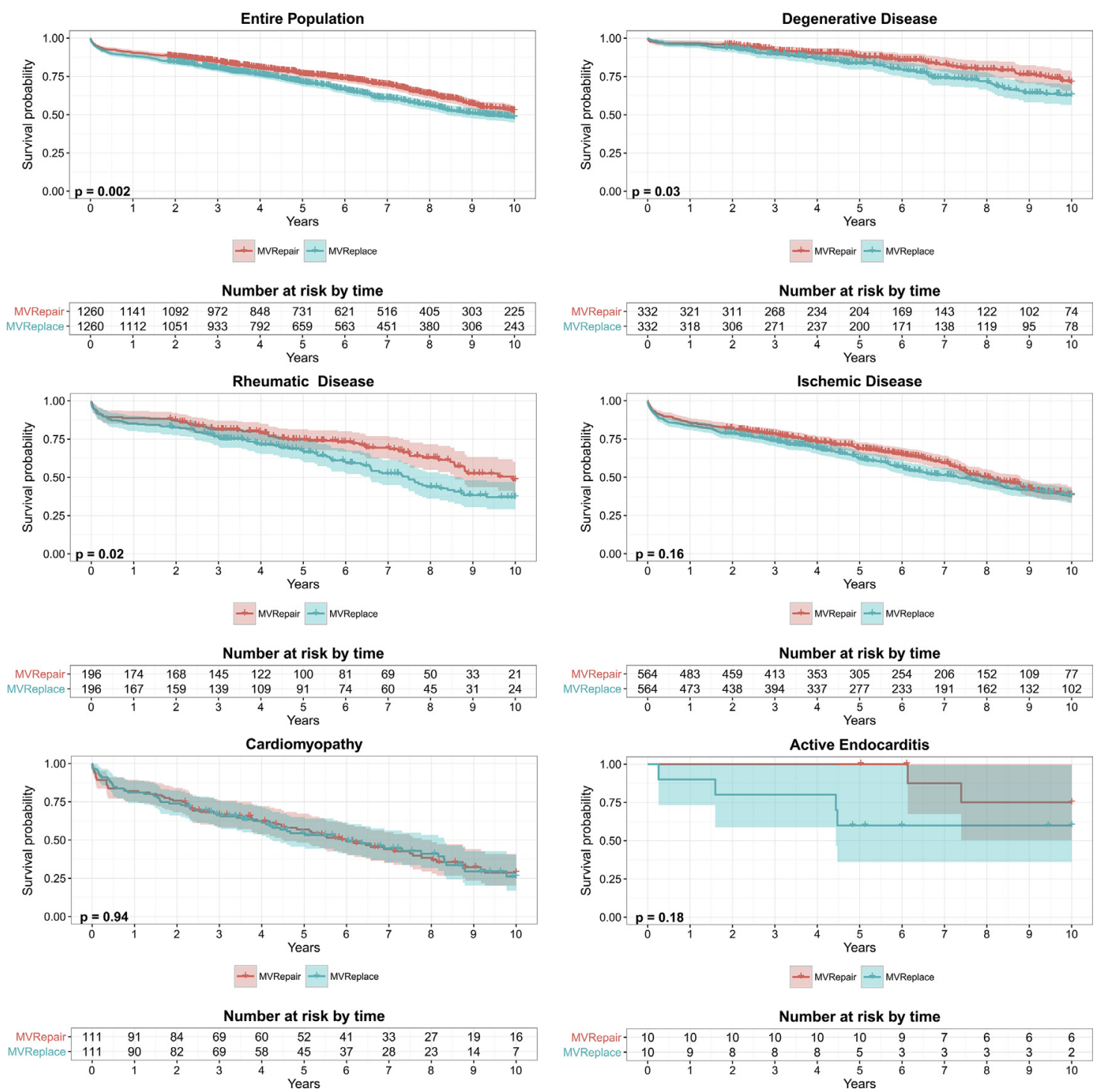

FIGURE E3. Kaplan-Meier survival curves for MVRepair (red) versus MVReplace (blue) for different causes of MR in matched patients. MVRepair, Mitral valve repair; MVReplace, mitral valve replacement. 
TABLE E1. Comorbidities and operative characteristics associated with MV surgery type after propensity matching

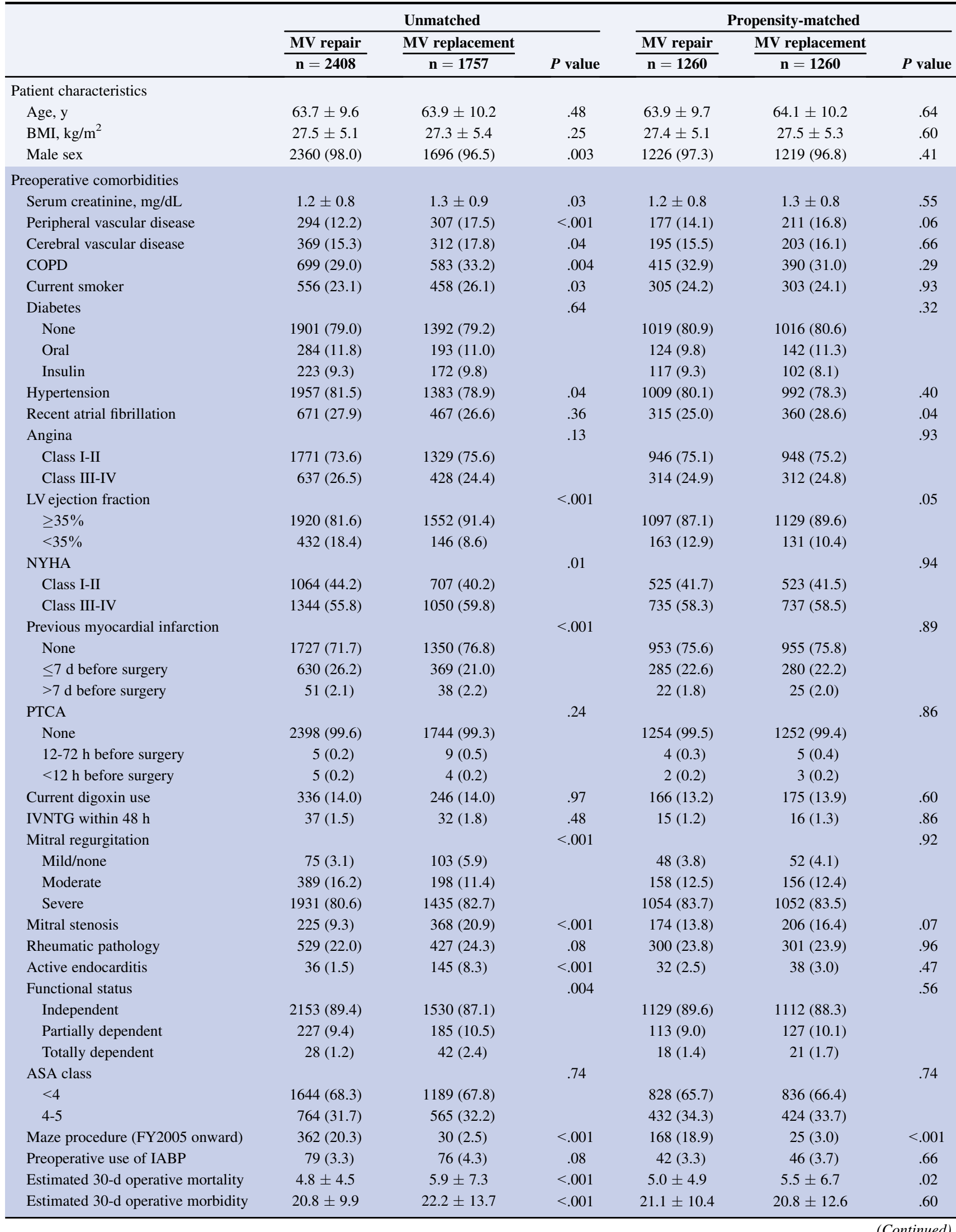


TABLE E1. Continued

\begin{tabular}{|c|c|c|c|c|c|c|}
\hline & \multicolumn{3}{|c|}{ Unmatched } & \multicolumn{3}{|c|}{ Propensity-matched } \\
\hline & $\frac{\text { MV repair }}{n=2408}$ & $\frac{\text { MV replacement }}{\mathrm{n}=1757}$ & $P$ value & $\begin{array}{c}\text { MV repair } \\
n=1260\end{array}$ & $\frac{\text { MV replacement }}{n=1260}$ & $P$ value \\
\hline \multicolumn{7}{|l|}{ Operative characteristics } \\
\hline Case status & & & $<.001$ & & & .61 \\
\hline Elective & $2214(92.0)$ & $1580(90.0)$ & & $1149(91.2)$ & $1156(91.8)$ & \\
\hline Urgent & $170(7.1)$ & $124(7.1)$ & & $89(7.1)$ & $88(7.0)$ & \\
\hline Emergent & $23(1.0)$ & $52(3.0)$ & & $22(1.8)$ & $16(1.3)$ & \\
\hline Concomitant CABG & $1164(48.3)$ & 715 (40.7) & $<.001$ & $556(44.1)$ & $527(41.8)$ & .24 \\
\hline Total bypass time, min & $161.8 \pm 58.0$ & $170.8 \pm 66.6$ & $<.001$ & $160.2 \pm 59.9$ & $171.6 \pm 68.5$ & $<.001$ \\
\hline Total ischemic time, min & $116.2 \pm 46.8$ & $124.5 \pm 52.3$ & $<.001$ & $113.3 \pm 46.4$ & $125.4 \pm 52.7$ & $<.001$ \\
\hline
\end{tabular}

Values are represented as mean \pm SD or n (\%). $M V$, Mitral valve; $B M I$, body mass index; $C O P D$, chronic obstructive pulmonary disease; $L V$, left ventricle; $N Y H A$, New York Heart Association; $P T C A$, percutaneous transluminal coronary angioplasty; $I V N T G$, intravenous nitroglycerin; $A S A$, American Society of Anesthesiologists; $F Y$, fiscal year; $I A B P$, intraaortic balloon pump; $C A B G$, coronary artery bypass grafting.

TABLE E2. Mortality by MV surgery type stratified by cause of mitral regurgitation

\begin{tabular}{|c|c|c|c|c|c|}
\hline \multirow[b]{2}{*}{ Cause } & \multirow[b]{2}{*}{ MV repair } & \multirow[b]{2}{*}{ MV replacement } & \multicolumn{3}{|c|}{ Propensity-matched odds of MV repair compared with replacement } \\
\hline & & & $\begin{array}{c}\text { Death within } 30 \mathrm{~d} \\
\text { OR }(95 \% \mathrm{CI})\end{array}$ & $\begin{array}{c}\text { Death within } 180 \mathrm{~d} \\
\text { OR }(95 \% \mathrm{CI})\end{array}$ & $\begin{array}{c}\text { Death within } 1 \text { y } \\
\text { OR }(95 \% \text { CI })\end{array}$ \\
\hline Degenerative & $572(57.8)$ & $418(42.2)$ & $1.77(0.50-6.15)$ & $0.91(0.39-2.13)$ & $0.78(0.35-1.71)$ \\
\hline Rheumatic & $409(61.0)$ & $262(39.0)$ & $1.11(0.45-2.73)$ & $0.82(0.44-1.54)$ & $0.73(0.49-1.34)$ \\
\hline Ischemic & $1266(60.9)$ & $815(39.2)$ & $0.81(0.51-1.31)$ & $0.70(0.50-0.99)$ & $0.87(0.64-1.19)$ \\
\hline Cardiomyopathy & $394(75.1)$ & $131(24.9)$ & $2.08(0.59-7.33)$ & $1.15(0.57-2.30)$ & $0.94(0.51-1.73)$ \\
\hline Endocarditis & $31(19.3)$ & $130(80.7)$ & N/A & N/A & N/A \\
\hline
\end{tabular}

Values are represented as $n(\%) . M V$, Mitral valve; $O R$, odds ratio; $C I$, confidence interval; $N / A$, not available. 